\title{
EDITORIAL
}

\section{The Choosing Wisely initiative: Does it have your back?}

\author{
David S Pisetsky*
}

As a subspecialty, rheumatology demands knowledge, intuition, and judgment to go along with a broad appreciation of the nuances and mysteries of internal medicine. Creativity is also part of the practice since many conditions in the purview of rheumatology lack established therapies that have received US Food and Drug Administration approval or testing in a controlled trial. Therefore, rheumatologists must create treatment plans, often on the fly (or by the seat of their pants), producing a succession of $n$-of- 1 trials in their practices. As if their current attributes were not enough, rheumatologists, like other providers, must now have wisdom and practice not only smartly but wisely. Such is the direction of Choosing Wisely.

For those of you who are not familiar with Choosing Wisely, this initiative of the American Board of Internal Medicine Foundation is a very timely and important effort to help reduce the cost of health care by encouraging providers to adopt more judicious and evidencebased ways to diagnose and treat illness. To meet this goal, professional medical organizations and societies are identifying situations in which cost reduction can be achieved by avoiding the overuse of low-yield (but expensive) diagnostic tests or prescription of therapies of marginal or questionable efficacy.

Although the goal of Choosing Wisely is highly laudable, many of the items targeted for reduction or elimination at this time are not that controversial or radical, nor will they require a major change in practice patterns of most providers. In common parlance, these items are low-hanging fruit. As a first step in cost containment, the Choosing Wisely initiative has stayed away (probably wisely) from big drivers of costs in the US, like the price of drugs, fragmentation of care, and lack of adequate preventative services. Certainly, in the US, the problem of uninsured patients continues to be vexing and could require the wisdom of Solomon as state governments go their various ways in response to Obamacare.

*Correspondence: piset001@mc.duke.edu

Duke University Medical Center, 151G, Durham VA Medical Center, Durham, NC 27705, USA
By its nature, the Choosing Wisely initiative is public and political as well as medical, designed to show the citizenry, including the government and payers, that physicians are willing to consider cost and partner with patients to constrain spending. This spending seems forever to increase to levels that everyone calls unsustainable, although, so far, the body politic has not screamed 'Enough is enough' and meant it. For its part, the American College of Rheumatology followed a rigorous and thoughtful approach to designate practices for the Choosing Wisely campaign (Table 1). Because the recommendations came from a Delphi process of organization members, the choices are informed and reasonable. Having never ordered Lyme serologies or used magnetic resonance imaging to stage rheumatoid arthritis, I may have already demonstrated my wisdom.

In the case of musculoskeletal disease, however, other groups have weighed in. The American College of Physicians says, 'Don't obtain imaging studies in patients with non-specific low back pain', whereas the American Academy of Family Physicians says, 'Don't do imaging for low back pain within the first six weeks, unless red flags are present'. The recommendations on back pain may not be easy to follow, because in the real world, patients with back pain can present with confusing signs and symptoms and often cannot date the onset of their problems. Furthermore, red flags are fortunately rare.

As I have learned many times, I do not know what nonspecific back pain is or how to differentiate it from the pain of a spondyloarthropathy, which, after all, can be pretty 'non-specific'. I am not alone in my uncertainty. I know a very experienced and savvy rheumatologist who missed the diagnosis of ankylosing spondylitis in himself, thinking that the nagging ache in the lower spine resulted from the pounding of too much tennis and jogging. He is now on a tumor necrosis factor blocker and doing smashingly, wondering how he had missed the diagnosis for over five years.

Our unit had its discussion of Choosing Wisely in a dreary conference room with three large bookcases filled with outdated editions of major texts. Our unit also includes clinical immunology and allergy, and one of our faculty members questioned the American Academy of 
Table 1. The American College of Rheumatology's top 5 list for choosing wisely

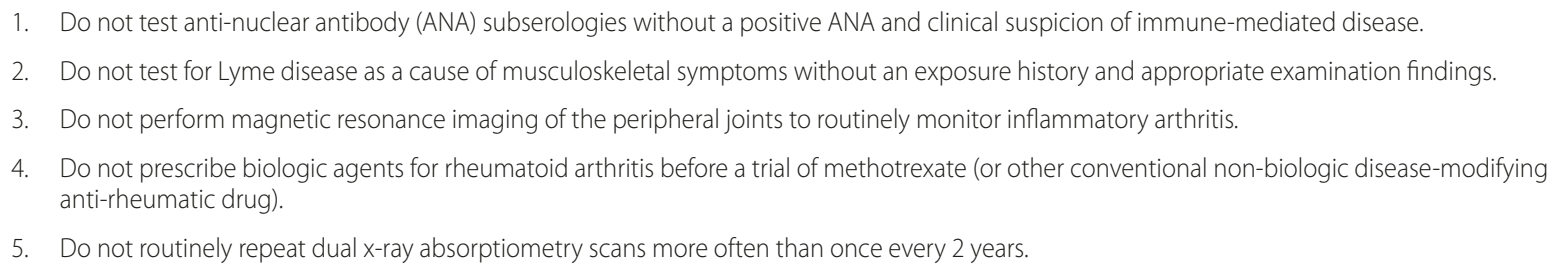

Reproduced with permission from John Wiley \& Sons [8].

Allergy, Asthma and Immunology recommendation about the use of spirometry in diagnosing and managing asthma. Similarly, I raised concerns about logistical issues in waiting until a fluorescent anti-nuclear antibody test is positive before ordering specific anti-nuclear antibodies. (Does that mean another clinic visit, which can be associated with a hefty facility fee?) Nevertheless, we all got on board and pledged to Choose Wisely in the future.

Although I support the Choosing Wisely initiative, I wish that the recommendations did not have such an Old Testament quality and embody, like the Ten Commandments, so many don'ts. I did find the words 'refrain' and 'avoid' while searching the lists on the Choosing Wisely website, but a few do's would have been nice. Also, I think that more recommendations on specific treatments to use and not eschew would have been very helpful given the enormous range of drugs now on the market.

As many rheumatologists know, back pain presents a conundrum not only because diagnosis is difficult but because treatment is difficult. For many patients, acute and chronic back pain can be severe, debilitating, and disabling. Often, such pain will not respond adequately to analgesics such as acetaminophen or a non-steroidal anti-inflammatory agent or measures such as heat or massage. Opioids then become an option, but a decision to prescribe opioids may be become problematic in the framework of Choosing Wisely, which suggests limiting diagnostic evaluations for back pain at least initially.

Because of the many societal as well as medical issues associated with controlled substances, physicians like to pursue at least some diagnostic testing prior to prescribing opioids, especially in individuals at high risk for drug side effects (for example, older individuals who could fall) or for complications of dependency and addiction. Recognizing the huge problem of opioid abuse in the population and the pressures on providers to prescribe these agents, the Federation of State Medical Boards has issued recommendations on prescribing controlled substances for pain; the recommendations emphasize the importance of a thorough patient evaluation in determining the need for a controlled substance. I wonder whether a history and physical exam are enough to make this judgment in the absence of some kind of imaging of the back.
For Choosing Wisely to be successful, the participation of patients is critical since they must partner with providers to accept a different kind of medical care at a time of cost containment and evolving expectations. Patients with pain, however, represent a special group because of the burden of their symptoms and the pressing need for relief. Unless a patient feels satisfied, it is not unusual for them to try a variety of interventions in quick succession, going from an orthopedist to a rheumatologist to a chiropractor to an acupuncturist. Indeed, studies suggest that 1 in 4 patients with pain will seek a new provider at least three times because they feel that their care is not optimal, meaning that their pain has not been adequately relieved.

In such a potentially conflicted setting, the patient's perception of the provider is critical. In my experience, patients appreciate and accept treatment recommendations when time is spent on the visit, complaints are taken seriously, and, yes, diagnostic testing is performed. Sometimes imaging is performed for no other reason than to allay patient worry and reduce fear and anxiety about the meaning of a surge of excruciating pain. While the yield on $\mathrm{x}$-rays may be low, an imaging study may be important to signal a commitment to find the diagnosis and develop a treatment plan that is based on the best evidence. Not infrequently, this plan will consider the risks and benefits of opioids if prescribed and, importantly, address psychological and life-style issues that may lead to abuse.

At present, many of the items in Choosing Wisely relate to diagnosis, and imaging is at the top of the list because of its expense. Clearly, there are many ways to reduce cost, whether by limiting the number of tests or reducing the cost of each. To me, both options should be on the table as this initiative goes forward. Certainly, choices should be the subject of intensive research that can fall under the rubric of comparative effectiveness. Given the number of skilled investigators, registries, and outcome assessment tools available for innovative real-world studies, recommendations on choices can be based not only on wisdom but on science.

Choosing Wisely is an excellent idea and the first attempts are in the right direction. My hope is that, on the next round, we confront some real choices - hard 
ones - and figure out what wisdom really is when it comes to the practice of medicine.

\section{Competing interests}

The author declares that he has no competing interests.

Published: 22 August 2013

\section{Suggested reading}

1. Arnbak B, Leboeuf-Yde C, Jensen TS: A systematic critical review on MRI in spondyloarthritis. Arthritis Res Ther 2012, 14:R55.

2. Cassel CK, Guest JA: Choosing wisely: helping physicians and patients make smart decisions about their care. JAMA 2012, 307:1801-1802.

3. De Leon-Casasola OA: Opioids for chronic pain: new evidence, new strategies, safe prescribing. Am J Med 2013, 126:S3-S11.

4. Deyo RA, Smith DHM, Johnson ES, Donovan M, Tillotson CJ, Yang X, Petrik AF, Dobscha SK: Opiods for back pain patients: primary care prescribing patterns and use of services. J Am Board Fam Med 2011, 24:717-727.
5. Lee J, Gupta S, Price C, Baranowski AP: Low back and radicular pain: a pathway for care developed by the British Pain Society. Br J Anaesth 2013, 111:112-120.

6. Rao VM, Levin DC: The overuse of diagnostic imaging and the choosing wisely initiative. Ann Intern Med 2012, 157:574-576.

7. Underwood M: Diagnosing acute nonspecific low back pain: time to lower the red flags? Arthritis Rheum 2009, 60:2855-2857.

8. Yazdany J, Schmajuk G, Robbins M, Daikh D, Beall A, Yelin E, Barton J, Carlson A, Margaretten M, Zell J, Gensler LS, Kelly V, Saag K, King C; American College of Rheumatology Core Membership Group (20 Collaborators): Choosing wisely: the American College of Rheumatology's Top 5 list of things physicians and patients should question. Arthritis Care Res (Hoboken) 2013, 65:329-339.

doi:10.1186/ar4257

Cite this article as: Pisetsky DS: The Choosing Wisely initiative: Does it have your back? Arthritis Research \& Therapy 2013, 15:117. 